\title{
OPINIÃO
}

\section{Aquecimento Global: evidências e preocupações}

Mauricio Serra*

Pode-se dizer que a relação entre o homem e a natureza é historicamente uma relação de conflitos na medida em que o homem tem contribuído significativamente para a modificação do ecossistema original. Entretanto, o divisor de águas nessa relação é a Revolução Industrial, uma vez que o equilíbrio ecológico, embora frágil, vinha sendo mantido até então. De fato, a Revolução Industrial, baseada no uso intensivo de combustíveis fósseis, propiciou uma intervenção nunca vista antes do homem na natureza, sendo a contínua expansão das atividades produtivas humanas um dos principais fatores de pressão na base de recursos naturais do planeta.

A preocupação ambiental, contudo, somente surge nos anos 60, particularmente com a publicação, em 1962, do livro Primavera Silenciosa (Silent Spring) de Rachel Carson, que alertava para os impactos causados pelo uso indiscriminado de produtos químicos, concebidos até aquele momento como a grande solução para o problema da fome no mundo, na cadeia agrícola e industrial sobre o meio ambiente, notadamente plantas e animais (as primaveras não mais teriam os cantos dos pássaros!!!).

Se o livro de Carson influenciou o nascimento do movimento ambientalista, a publicação pelo Clube de Roma, em 1972, do livro The Limits to Growth, que sublinhava que a busca ininterrupta por crescimento econômico causaria sérios e irreversíveis impactos sociais e ambientais negativos, foi decisiva para que a questão ambiental ganhasse uma dimensão muito maior, que acabou culminando na formulação do conceito de sustentabilidade. $\mathrm{Na}$ realidade, a crítica ambiental foi de fundamental importância não só para despertar uma nova consciência ecológica, mas também por propiciar que outras ciências, principalmente a econômica, pudessem incorporar a questão ambiental em seus arcabouços teóricos.

Embora avanços possam ser notados e citados, a verdade é que eles têm se mostrado insuficientes, e muitas vezes inócuos, para se compreender e, consequentemente, se resolver o grave problema do aquecimento global. $\mathrm{Na}$ verdade, as mudanças climáticas vêm proporcionando fenômenos tais como enchentes, furacões, incêndios em florestas e secas

\footnotetext{
* Professor do Departamento de Economia e do Programa de Pós-Graduação em Desenvolvimento Econômico da Universidade Federal do Paraná (PPGDE/UFPR). Endereço eletrônico: serra@,ufpr.br.
} 
com tamanha intensidade que todos os seres humanos, direta ou indiretamente, podem vir a ser afetados por suas conseqüências.

Há um consenso entre os cientistas de que o aquecimento global é provocado pelo aumento da concentração de gases poluentes derivados da queima de combustíveis fósseis, como, por exemplo, a gasolina e o diesel. São estes gases, tais como o ozônio, o gás carbônico e o monóxido de carbono os responsáveis pela formação de uma camada de poluentes que geram, em função da dificuldade de sua dispersão, o conhecido efeito estufa. Contribuem igualmente para o aquecimento global o crescente desmatamento e a queimada de florestas na medida em que os raios solares atingem o solo e irradiam calor na atmosfera, que é retida em grande parte pela cama de poluentes, sendo o aumento da temperatura da Terra o resultado desse processo.

O aquecimento global pode provocar várias e profundas conseqüências. A primeira é o aumento do nível dos oceanos em virtude do derretimento das calotas polares, sendo a submersão de cidades litorâneas um possível efeito do aumento do nível das águas oceânicas. Uma segunda é a quantidade e o padrão de precipitação, o que pode provocar enchentes e secas. Uma terceira conseqüência é o aumento de furacões e ciclones em função de mudanças extremas, tanto na freqüência quanto em intensidade, nas condições meteorológicas. Outras conseqüências geradas pelo aumento de temperatura incluem o crescimento (e o surgimento) de áreas desérticas, a extinção de várias espécies animais e vegetais, o aumento na escala de doenças e mudanças na produção agrícola.

A situação é, de fato, extremamente preocupante, principalmente quando se observam os dados a respeito da mudança climática no planeta. De acordo com o IPCC ${ }^{62}$ $\left(2007^{63}\right)$, a principal autoridade mundial sobre aquecimento global, as emissões dos gases de efeito estufa têm aumentado desde os tempos pré-industriais, sendo que este aumento foi de 70\% no período de 1970-2004. Um aspecto importante a ser observado é que o principal responsável pelo acentuado crescimento das emissões dos gases de efeito estufa no mundo nesse período é o setor energético, que teve um aumento de $145 \%$. O crescimento das

\footnotetext{
62 O IPCC (Intergovernmental Panel on Climate Change) é um organismo intergovernamental criado, em 1988, pela WMO (World Meteorological Organization) e a UNEP (United Nations Environment Program) com o objetivo de fornecer conselhos científicos independentes sobre a complexa e importante temática da mudança de clima.

${ }^{63}$ IPCC Fourth Assessment Report: Summary for Policymakers. Disponível em: www.ipcc.ch
} 
emissões diretas ${ }^{64}$ nesse mesmo período de tempo veio do setor de transporte, com $120 \%$ de aumento; da indústria, com 65\%; e do uso da terra, da mudança do uso da terra e da floresta $\left(\mathrm{LULUCF}^{65}\right)$, com $40 \%$.

Outro dado bastante relevante é que os países listados no anexo I da UNFCCC (United Nations Framework Convention on Climate Change) em 2004 detinham 20\% da população mundial, produziam 57\% do PIB mundial (baseado na Paridade do Poder de Compra) e eram responsáveis por cerca de $46 \%$ das emissões dos gases de efeito estufa no mundo, conforme pode ser verificado na figura 1 abaixo.

\section{Figura 1. A Distribuição em 2004 das emissões dos gases de efeito estufa pela população de diferentes grupos de países.}

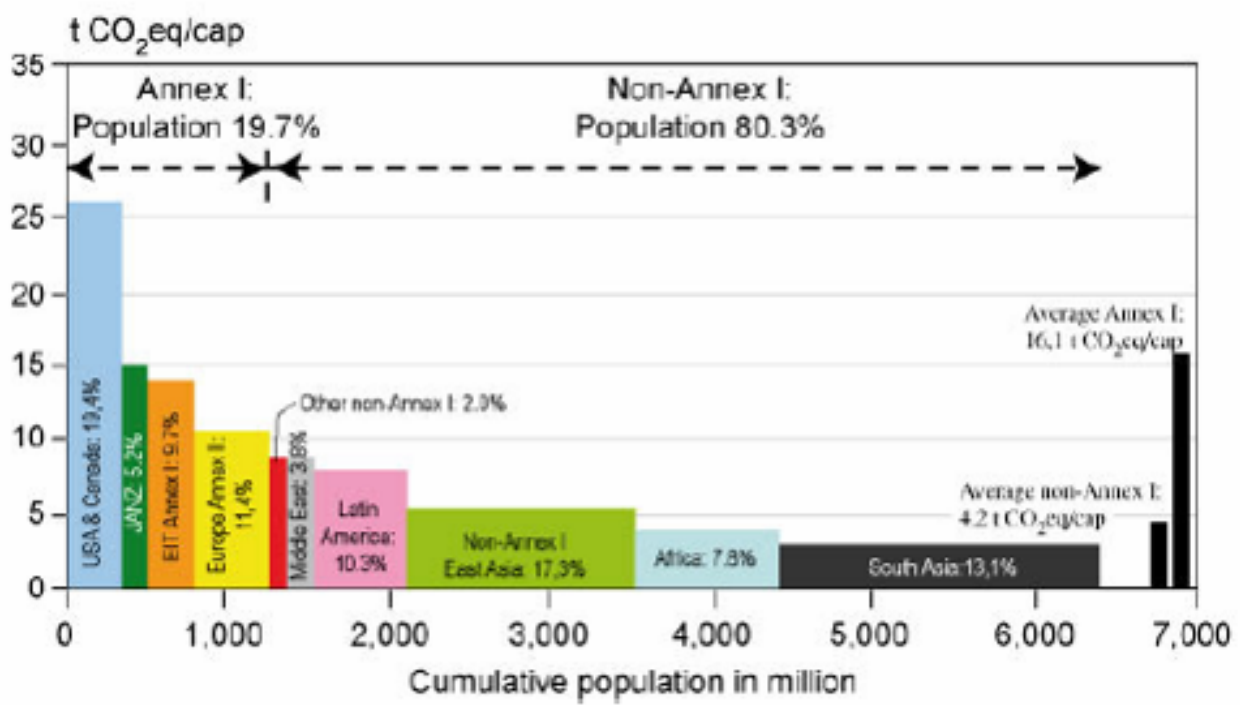

Fonte: IPCC, 2007

Obs: o percentual nas barras indica a parcela da região na emissão dos gases de efeito Estufa no mundo.

Embora seja verdade que a implementação de diversas políticas voltadas à segurança energética, à mudança climática e ao desenvolvimento sustentável tenha contribuído para a redução das emissões dos gases de efeito estufa em distintos setores e em muitos países, esses resultados são insuficientes para reverter o crescimento mundial das emissões. Neste sentido,

${ }^{64}$ As emissões diretas em cada setor não incluem as emissões do setor de eletricidade para a eletricidade consumida nos setores de construção, industrial e agrícola, ou de emissões provenientes de operações de refino para o fornecimento de combustível destinado ao setor de transporte.

${ }^{65}$ Land Use, Land Use Change and Forestry (LULUCF) é utilizado aqui para descrever as emissões agregadas de $\mathrm{CO} 2, \mathrm{CH} 4, \mathrm{~N} 2 \mathrm{O}$ provenientes do desflorestamento, da biomassa e da queimada, da redução da biomassa em função da extração de madeira e do desflorestamento, da redução da turfa e do fogo de turfa. Isto é mais amplo do que as emissões do desflorestamento, que está incluído como um subsetor. 
algumas projeções feitas pelo IPCC mostram claramente que as temperaturas da superfície terrestre devem variar entre $1,1^{\circ} \mathrm{C}$ e $6,4^{\circ} \mathrm{C}$ até 2100 , sendo $\mathrm{B} 1$ o melhor cenário na medida em que a temperatura é de $1,8^{\circ} \mathrm{C}$ (a faixa provável é entre $1,1^{\circ} \mathrm{C}$ e $2,9^{\circ} \mathrm{C}$ ), enquanto A1FI é o pior deles, pois a temperatura é de $4,0^{\circ} \mathrm{C}$ (e faixa provável é entre $2.4^{\circ} \mathrm{C}$ e $6.4^{\circ} \mathrm{C}$ ), conforme a figura 2.

Figura 2. Aquecimento da Superfície Global, 1900-2100.

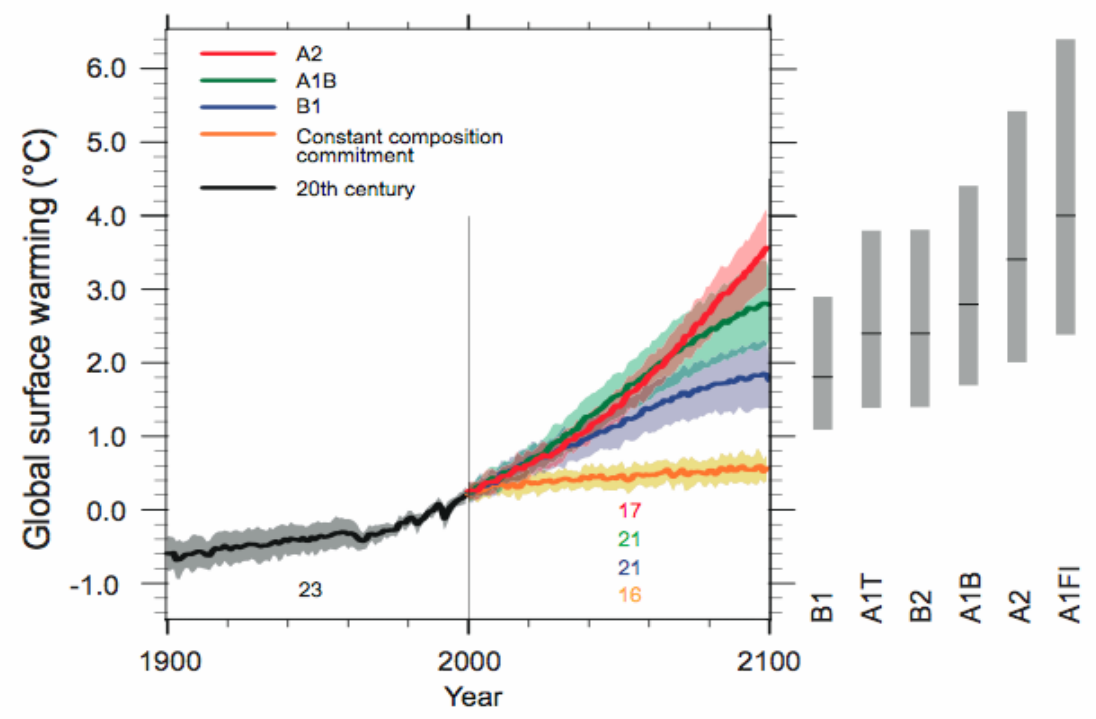

Fonte: Pachauri, R.K. \& Jallow, B., $2007^{66}$.

Estas projeções foram feitas para 2100, mas há um consenso entre os especialistas de que o aquecimento global e o aumento do nível dos oceanos continuarão ainda por muito mais tempo, mesmo que os níveis dos gases de efeito estufa se mantenham estáveis. Além das já consideráveis preocupações com as graves conseqüências do aquecimento do planeta e, principalmente, da irreversibilidade desse processo, a publicação de uma reportagem especial da revista norte-americana Newsweek, em abril de 2007, acrescenta mais uma ao extenso rol de preocupações, sendo que esta é destinada principalmente aos países em desenvolvimento.

A mensagem é bem simples: a continuação do aumento, mesmo que modesto, da temperatura da Terra acarretará em ganhadores e perdedores no processo de mudança climática. A grande ironia da história ou do destino é que, segundo a reportagem da Newsweek, os perdedores serão os países mais pobres, ou seja, aqueles que estão no hemisfério sul da

66 Pachauri, R.K. \& Jallow, B. (2007), Climate Change 2007: The Physical Science Basis, Working Group I Contribution to the IPCC Fourth Assessment Report, paper presented in Nairobi. Disponível em: www.ipcc.ch. 
terra, ao passo que os ricos países no norte serão os beneficiados nesse processo e, consequentemente, tenderão a ficar ainda mais ricos do que já são.

Em função dessa mudança a ser propiciada pelo aquecimento global, muitas empresas têm encarado isso como um novo desafio que gerará oportunidades econômicas, sendo importante estar preparado para enfrentar e, principalmente, lucrar com uma nova e bem provável realidade.

Como se já não bastasse o tremendo fosso existente entre países desenvolvidos e em desenvolvimento, o aquecimento global poderá contribuir para aumentá-lo ainda mais num futuro não tão longínquo, o que torna muito maior o esforço destes últimos países para superar as adversidades que, provavelmente, virão pela frente.

A necessidade de ação é algo imperativo não só para mitigar os impactos negativos advindos da mudança climática no mundo, mas também para que um futuro planeta mais aquecido não se torne mais excludente. A concepção de que o aquecimento global pode vir a ser um bom negócio e que os ajustes e as adaptações podem ser resolvidos por meio das livres forças do mercado é extremamente míope e perigosa, uma vez que as distorções entre ricos e pobres no mundo tenderão a se acentuar. 
